\title{
Association Between Tooth Loss and Cancer Mortality in Elderly Individuals
}

\author{
Toshihiro Ansai ${ }^{1}$ and Yutaka Takata ${ }^{2}$ \\ ${ }^{1}$ Division of Community Oral Health Science, \\ 2Division of General Internal Medicine, Kyushu Dental College \\ Japan
}

\section{Introduction}

Over the past decade, much evidence has emerged showing an association between oral health and systemic health condition, though few have studied the relationship between impaired dental status and cancer mortality. Although tooth loss is a good clinical indicator of poor oral health because it is less prone to measurement error, results of epidemiological research using tooth loss as a measurement of oral health are limited, likely because periodontal disease has been a particular focus of attention in recent years. The aim of this study was to review the outcomes in other reports that suggest associations between dental status, especially tooth loss, and cancer mortality and morbidity. Furthermore, several potential mechanisms related to those associations are discussed.

\section{Assessment of dental status: Which is better, tooth loss or periodontal disease?}

Most studies published to date have used tooth loss and/or periodontal disease to assess dental status. However, a persistent problem with this point is that diagnosis of periodontal disease is subjective and not straightforward, and it is questionable whether periodontal indices such as probing can reliably reveal underlying disease status. First, the process of calibration between examiners performing periodontal assessments, with both probing and non-probing indices, is time consuming. When several dentists are used as examiners, they must be calibrated both before and during the survey using some of the same subjects or volunteer patients. The kappa value determined by replicate examinations by probing of periodontal tissue is generally not high, at most around 0.7 to 0.8 . Second, different cut-offs for periodontal disease have been used (Hujoel et al., 2000; Wu et al., 2000). In contrast, measurment of the number of missing teeth is straightforward and seems to be a reliable indicator of dental health status. Therefore, in the present study, we focus on research that investigated the associations between tooth loss and cancer risk.

Tooth loss typically results from trauma, caries, or periodontal disease, with that in older individuals more likely to be caused by periodontal disease, while tooth loss in younger ages is usually caused by dental caries (Papapanou et al., 1996). Thus, we consider that tooth loss as described in this review is an indicator of periodontal disease and the 
number of missing teeth can be viewed as an index of lifetime accumulation of poor oral health.

\section{Methods for assessment of tooth loss}

In general, 2 methods are used for assessment of tooth loss. One is an oral examination by a dentist or tooth counting by medical personnel, while the other is self-reporting by use of a questionnaire that includes the question, "How many teeth do you have remaining?". Three reports (Michaud et al., 2008; Hiraki et al., 2008; Stolzenberg-Sollomon et al., 2003) have been presented based on answers to that question, while 3 different reports (Cabrera et al., 2005; Tu et al., 2007; Abnet et al., 2005) were of results obtained by direct data collection using panoramic photographs or oral examinations. Previous report suggested that selfreported number of teeth is highly correlated with actual number of teeth found in clinical assessments of a general population (Douglass et al., 1991).

\section{Relationship between tooth loss and cancer mortality}

\subsection{Tooth loss and all-site cancer mortality}

To date, 4 known studies have reported the associations between tooth loss and risk of cancer death (Abnet et al., 2005; Cabrera et al., 2005; Tu et al., 2007; Michaud et al., 2008). When reviewing those articles, it is important to note carefully whether the outcomes investigated were morbidity or mortality, as the former 3 studies were based on mortality, while the most recent was based on the incidence of cancer, or morbidity. Here, we would like to present a step by step review of 3 of those reports (Table 1).

\begin{tabular}{|c|c|c|c|c|c|c|c|}
\hline Authors & Year & Nation & Length & $\begin{array}{l}\text { Sample } \\
\text { size }\end{array}$ & Expose & Outcome & $\begin{array}{l}\text { HR } \\
(95 \% \text { CI })\end{array}$ \\
\hline $\begin{array}{l}\text { Cabrera } \\
\text { et al. }\end{array}$ & 2005 & Sweden & 24 years & $\begin{array}{l}1,462 \\
\text { women }\end{array}$ & $\begin{array}{l}>10 \text { missing } \\
\text { teeth }\end{array}$ & Mortality & $1.16(0.90-1.49)$ \\
\hline $\begin{array}{l}\text { Michaud } \\
\text { et al. }\end{array}$ & 2008 & USA & 18 years & 48,375 men & $\begin{array}{l}0-16 \text { vs. } 25- \\
32 \text { teeth }\end{array}$ & Morbidity & $\begin{array}{l}1.26(1.15-1.38) \\
1.09 * \\
(0.99-1.20)\end{array}$ \\
\hline $\begin{array}{l}\text { Ansai, et } \\
\text { al. }\end{array}$ & 2010 & Japan & 12 years & $\begin{array}{l}697 \text { 80-yr- } \\
\text { old }\end{array}$ & $\begin{array}{l}\text { Edentulous } \\
\text { vs. } 20 \text { or } \\
\text { more teeth }\end{array}$ & Mortality & $1.77(0.76-4.17)$ \\
\hline
\end{tabular}

Table 1. Summary of longitudinal studies evaluating relationship between tooth loss and allsite cancer mortality/morbidity

*Fully adjusted model

The association between tooth loss and cancer mortality is controversial. A prospective cohort study of 1462 Swedish women study showed there were no associations between number of missing teeth and cancer mortality over a period of 24 years [hazard ratio (HR) $1.16,95 \%$ confidence interval (CI) $0.90-1.49$ per 10 missing teeth] after adjustments for age, waist-hip ratio, body mass index, smoking, age at first birth, parity, and husband's 
occupational category, while there was a significant association between tooth loss and cardiovascular disease mortality (HR, 1.34, 95\% CI, 1.05-1.71) after adjustments for the same confounding factors (Cabrera et al., 2005). A study of US male health professionals showed that fewer teeth at baseline was associated with a significant increase in incidence rate of total cancer for those with 0-16 teeth vs. those with 25-32 teeth (HR, 1.26, 95\% CI, 1.15-1.38), with adjustments for age, ethnic origin, physical activity, history of diabetes, alcohol consumption, body mass index, geographical location, height, calcium intake, total calorific intake, red meat intake, fruit and vegetable intake, and vitamin D score (Michaud et al., 2008). However, in a fully adjusted model that included smoking history (never, past quit $\leq 10$ years, past quit $>10$ years, current 1-14 cigarettes per day, 15-24 cigarettes per day, 25+ cigarettes per day) and pack-years, the association was insignificant for tooth loss (HR, 1.09, 95\% CI, 0.99-1.20).

On the other hand, evidence from Asian populations is scarce and only 3 reports are known to date. One is a case-control study conducted in Japan (Hiraki et al., 2008), and the other 2 are prospective cohort studies showing an association between tooth loss and cancer mortality (Abnet et al., 2005; Ansai et al., 2010). The case-control study was based on a Hospital-based Epidemiologic Research Program in Japan, and investigated associations between tooth loss and incidence rates of 14 common cancers. Although the risk for total cancer was not described, their findings showed that a greater number of missing teeth was associated with increased risks of head and neck, esophageal, and lung cancers, and decreased risk of prostate cancer (Hiraki et al., 2008). Also, for head and neck and esophageal cancers, stratified analyses by sex and age showed clear associations between tooth loss and cancer risk in women and younger subjects, but less clear associations in men and older subjects. In another Japanese survey, which was our prospective cohort study of 697 Japanese individuals (80 years old at baseline), there were no associations between number of teeth (treated as a categorical variable) and cancer mortality during a 12-year follow-up period (HR, 1.77; 95\% CI, 0.76-4.17 for edentulous vs. those with 20 or more teeth), while a significant association was observed between the number of teeth and all causes of mortality (HR, 1.66; 95\% CI, 1.17-2.35 for edentulous vs. those with 20 or more teeth), with adjustments for gender, smoking status, serum total cholesterol, fasting serum glucose, body mass index, and systolic blood pressure (Ansai, 2010). A population study conducted in China did not mention an association between tooth loss and total cancer mortality, though it showed that tooth loss significantly increased the risk of death from upper gastrointestinal cancer ( $\mathrm{HR}, 1.35,95 \% \mathrm{CI}, 1.14-1.59)$, while there were no significant associations between tooth loss and death from other cancers (Abnet et al., 2005).

\subsection{Tooth loss and specific-site cancer mortality}

As noted above, epidemiologic studies have associated tooth loss with a higher risk of cancer. Next, recent evidence is presented concerning the associations between tooth loss and morbidity/mortality due to cancer in specific sites (Table 2).

\subsubsection{Tooth loss and oral cancer morbidity}

There are no known reports regarding associations between tooth loss and mortality due to oral cancer. Although case-control studies have been reported, the relationship between 


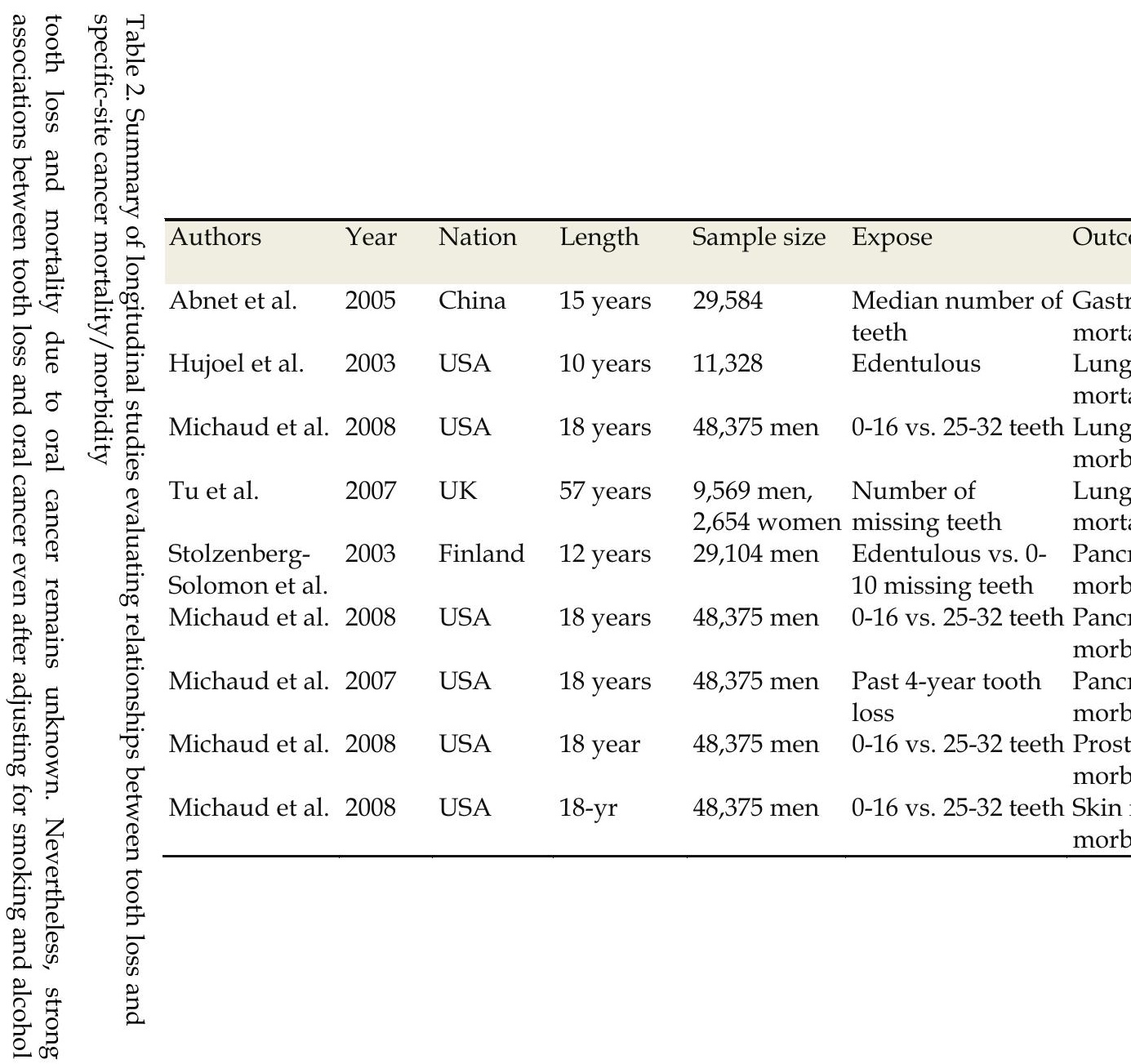


consumption have been noted (Zheng et al., 1990; Bundgaard et al., 1995; Marshall et al., 1992; Garrote et al., 2001; Rosenquist et al., 2005), and those reports were recently reviewed (Meyer et al., 2008). After removing smoking and alcohol consumption as factors, those results showed that tooth loss increases the risk of oral cancer by 2- to 3-fold. In addition, those findings revealed significant interactions between tooth loss and smoking and alcohol use. A more extensive study recently explored the relationship between oral health status and squamous cell carcinoma of the head and neck and esophagus (Guha et al., 2007). Their findings indicated that as oral health condition worsened, the risks of cancers of the head, neck, and esophagus increased. However, scant information regarding those associations in Asian populations is available. One report noted a significant association between tooth loss and esophageal squamous cell carcinoma in a Chinese cohort (Abnet et al., 2001), while Hiraki et al. reported a significant positive association between tooth loss and risk of head and neck and esophageal cancers in a Japanese population after adjustment for potential confounders in a case-control study (Hiraki et al., 2008).

\subsubsection{Tooth loss and gastric cancer mortality}

Two early studies indicated that tooth loss may be associated with gastric cancer incidence (Wolff \& Lauter, 1976; Demirer et al., 1990). In the 21st century, 2 studies from China provided information on the link between tooth loss and gastric cancer (Abnet et al., 2001, 2005). The population for both studies was recruited from the Linxion province, where provision of dental care is poor and there is a high prevalence of gastric cancer. In the former study, tooth loss, especially in subjects below the age of 50 years, was significantly associated with gastric non-cardia adenocarcinoma (HR, 3.3, 95\% CI, 0.85-12.4), following adjustments for age, gender, smoking, and alcohol use. In another follow-up study of the same population, there was a significant relationship found between tooth loss and mortality due to gastric cancer, as tooth loss was associated with a 35\% increased risk. Also, the risk for gastric cancer associated with tooth loss was higher in male never-smokers than in male smokers (HR, 1.59, 95\% CI, 1.03-2.45; HR, 1.39, 95\% CI, 1.06-1.83, respectively). In contrast, there was not a significant association in females. Age was also shown to be a significant effect modifier of gastric cancer mortality and tooth loss association. In that study, 547, 1121, and 957 cases of gastric cancer were found in subjects aged $<50,50-59$, and $\geq 60$ years, respectively, with HRs of 1.25 (95\% CI, 1.06-1.48), 1.18 (95\% CI, 1.05-1.33), and 0.99 (95\% CI, 0.87-1.13), respectively, for those 3 age strata.

\subsubsection{Tooth loss and lung cancer mortality}

Three studies of the association between tooth loss and lung cancer mortality/morbidity have been presented (Hujoel et al., 2003, Tu et al., 2007; Michaud et al., 2008). The earliest presents data from the NHANES I epidemiological follow-up study (Hujoel et al., 2003). The subjects in that study underwent periodontal assessments based on the Russell Index, and included those with and without periodontal disease, gingivitis, and an edentulous condition. Those with an edentulous condition, which was defined as total tooth loss, had an elevated risk for mortality due to fatal neoplasms in the lung and bronchus. After adjustments for demographic factors and risk factors for lung cancer, edentulous condition had an HR of 1.37 (95\% CI, 0.72-2.60). In the survey of health professionals in the US, fewer 
teeth at baseline (0-16) was associated with an increase in morbidity from lung cancer (HR, 1.70, 95\% CI, 1.37-2.11) as compared to subjects with 25-32 teeth (Michaud et al., 2008). However, in never-smokers, no association was noted for lung cancer. On the other hand, there was no significant association between tooth loss as a continuous variable and lung cancer mortality in a Scottish study, both with adjustment for baseline smoking status (HR, 1.01, 95\% CI, 0.97-1.06) and without (HR, 1.02, 95\% CI, 0.98-1.07) (Tu et al., 2007). Even when tooth loss was treated as a categorical variable, similar results have been obtained, as HRs were 1.29 (95\% CI, 0.81-2.06) for 5-8 missing teeth and 1.36 (95\% CI, 0.71-2.61) for $\geq 9$ missing teeth, following adjustments (Tu et al., 2007).

\subsubsection{Tooth loss and pancreatic cancer incidence}

There is increasing evidence that tooth loss is a risk factor for pancreatic cancer. A Finnish study showed that tooth loss, especially edentulous condition, was associated with an increasing cancer incidence risk in a prospective cohort study conducted for 12 years (Stolzenberg-Solomon et al., 2003). The multivariate HR was 1.63 (95\% CI, 1.09-2.46; P for trend, 0.02) for edentulism as compared with missing teeth (0-10 teeth) and 1.23 (95\% CI, 0.82-1.85) for 11-31 missing teeth as compared with 0-10 missing teeth, with adjustments for age, number of years of smoking, education, urban living, and height. More convincing information has come from the US health professionals survey (Michaud et al., 2007). Their data showed that tooth loss was not significantly associated with an increased incidence of pancreatic cancer. However, another study of the same sample showed that tooth loss during the past 4 years was significantly associated with pancreatic cancer incidence (Michaud et al., 2007). In that study, the multivariate HR was 1.61 (95\% CI, 1.13-2.31) with adjustment for multiple confounders including age, smoking history, profession, race, geographic location, history of diabetes, body mass index, height, history of cholecystectomy, nonsteroidal anti-inflammatory drug use, multivitamin use, dietary intake of fruits and vegetables, vitamin D, calcium, sucrose, total calories, and baseline number of teeth. Furthermore, periodontal disease with recent tooth loss in the past 4 years was associated with an increase in pancreatic cancer, as compared with no periodontal disease and no recent tooth loss (HR, 2.71, 95\% CI, 1.70-4.32).

\subsubsection{Tooth loss and prostate cancer incidence}

A case-control study conducted in Japan showed that a decreased number of remaining teeth was associated with the incidence of prostate cancer with a lower odds ratio (OR) of 0.49 (95\% CI, 0.19-1.26) (Hiraki et al., 2008), while a similar finding was reported in follow-up investigation of the US male health professionals study (Michaud et al., 2008). The multivariate HR value reported in that study was 0.7 (95\% CI, 0.50-0.97) for subjects with 0 16 teeth vs. those with 25-32 teeth. Interestingly, both results showed significant inverse associations, though interpretation of this association requires caution, as unmeasured confounders could explain the association, which is the case with any epidemiological study.

\subsubsection{Tooth loss and incidence of melanoma of the skin}

A significant inverse association between tooth loss and the incidence of melanoma of the skin was found in the US male health professionals follow-up study (Michaud et al., 2008). 
However, this is the only evidence presently available, since no other survey concerning such an association has been performed. The multivariate $\mathrm{HR}$ was 0.60 (95\% CI, 0.40-0.89) with adjustments for age, ethnic origin, physical activity, history of diabetes, alcohol consumption, body mass index, geographical location, height, calcium intake, total calorific intake, red-meat intake, fruit and vegetable intake, and vitamin D score. Furthermore, even in a fully adjusted model including smoking history and pack-years, the association for tooth loss remained significant (HR, $0.62,95 \% \mathrm{CI}, 0.41-0.93)$.

\subsubsection{Tooth loss and other cancers}

A recent Japanese case-control study investigated the associations between tooth loss and other cancers (Hiraki et al., 2008), and reported no significant associations for cancers of the colon, liver, breast, uterus, ovary, bladder, thyroid, and lymphoma. Another report conducted in the United States found showed no significant associations between tooth loss and oropharyngeal, colorectal, kidney, bladder, hematopoietic, and brain cancers (Michaud et al., 2008). In contrast, that report found a significant association between history of periodontal disease and kidney cancer, and between history of periodontal disease and hematopoietic cancers.

\section{Possible mechanism for relationship between tooth loss and cancer mortality/morbidity}

As noted above, associations between tooth loss and cancer mortality/morbidity have been reported, though the potential causal mechanism remains unknown. As for the primary mechanisms behind the associations, 2 have been hypothesized; a chronic inflammation pathway and a nutritional pathway. On the other hand, other possible factors may be more indirect, such as sarcopenia, brain activity, quality of life (QOL), and socioeconomic status. Here we present several findings to support these pathways and factors.

\subsection{Chronic inflammation pathway}

Tooth loss in older age is a consequence of chronic bacterial infections, such as periodontitis (Papapanou, 1996). Thus, tooth loss may be an indicator of past bacterial load and perhaps the presence of endogenous bacteria in general. Host response to periodontal disease might lead to systemic exposure to proinflammatory cytokines. For example, host response to Helicobacter pylori-induced inflammation has been reported to play a role in gastric cancer (Correa P et al., 2003). In this regard, periodontal disease may increase the risk of cancer by chronic release of inflammatory mediators. Another important point is that periodontal disease may influence carcinogenesis through increased generation of carcinogens, such as nitrosamines. Oral flora is known to preferentially produce carcinogenic by-products and is more effective for reducing nitrates to nitrites, which then spontaneously react with amines and become converted to carcinogenic nitrosamines (Shapiro KB et al., 1991). Another metabolic product of significance that has carcinogenic potential is acetaldehyde (Homann et al., 2001). These can spontaneously combine with other dietary components to form nitrosamines. Periodontal disease and attendant increased loss of teeth might result in greater endogenous nitrosamine production, and an associated greater risk of cancer. 


\subsection{Nutritional pathway}

Tooth loss reduces chewing ability and may lead to consumption of a less healthy diet, which may be associated with cancer. Studies performed in the United Kingdom (Sheiham et al., 2001) and Japan (Kanmori et al., 2003) found that poor chewing ability influences total calorie intake. Also, tooth loss may influence the types and intake of nutrients. Yoshihara et al. (2005) reported a comparison of nutrient intake between individuals with 20 or more teeth and those with less than 20 teeth. They found that the former group had increased intake of vegetables and fish as well as vitamins, including vitamin D, vitamin B1, vitamin B6, niacin, and pantothenic acid. The Japanese National database study also reported that subjects with reduced chewing ability had lower intake of minerals, such as calcium, magnesium, and zinc, as well as dietary fiber, while they had much more starch intake. In the UK, subjects with lower chewing ability had lower intake of dietary fiber, proteins, calcium, iron, niacin, vitamin C, and vitamin E (Sheiham et al., 2001). Furthermore, in the report of male health professionals performed in the US, subjects who lost 5 or more teeth during an 8-year period had significantly lower intake of dietary fiber, fruit, polyunsaturated fat, and vitamin $\mathrm{E}$ as compared to subjects who had lost no teeth (Hung et al., 2003). In another report conducted in the US, edentulous subjects had lower intake of dietary fiber, carotenes, and vitamin $\mathrm{C}$ than fully dentate subjects (Nowjack-Raymer et al., 2003). In general, vitamins such as vitamin C, vitamin E, and carotene are known to be anticancer nutrients. The consumption of vegetables, specifically bright red, green, and yellow vegetables, and solid fruit may lead to prevention of diseases including cardiovascular or gastrointestinal diseases (Joshipura et al., 1999; Cheng et al., 1996). The WHO recommends intake of vegetables in amounts greater than $400 \mathrm{~g} /$ day. In a Japanese survey, subjects with lower chewing ability had a higher prevalence of gastrointestinal disease (Ikebe et al., 1999), with a similar outcome reported elsewhere (Cheng et al., 1996). Furthermore, the effects of denture wearing have also been studied. Subjects with dentures had a lower intake of vegetables and dietary fiber as well as vitamin C and beta-carotene (Nowjack-Raymer et al., 2003), while a recent report also found that subjects wearing any kind of removable dentures had lower intakes of vegetables and fruit with associated increased nutritional risk as compared to subjects with fixed dentures (Tsai et al., 2011).

\subsection{Sarcopenia}

Sarcopenia is defined as muscle power decline or decreased muscular volume with aging, leading to decreased levels of basal metabolism and energy consumption by the whole body, which results in lower energy intake and a decrease in synthesis of proteins in the body. To the best of our knowledge, no study concerning the association between chewing ability (tooth loss) and sarcopenia has been presented, though it is considered that elderly individuals with sarcopenia may also develop the condition in the oral cavity region, which has been supported by several reports. For example, subjects with stable occlusion, eg., Eichner index (EI; Eichner, 1955) Class A were shown unlikely to stumble (Yoshida, 2005). EI, long used as an indicator of occlusal condition, are based on existing natural tooth contacts between the maxilla and mandible in the bilateral premolar and molar regions. Class A represents contact in all 4 support zones. Some reports have been presented regarding associations between stable occlusion and physical fitness ability (Yamaga et al., 2002), chewing ability and physical fitness (Takata et al., 2004), and walking speed and oral 
function (Okada et al., 2011). In a recent longitudinal study of Japanese elderly subjects, partial or complete loss of occlusion was associated with a decline in leg extensor power or decrease in one-leg standing time with eyes open (Okuyama et al., 2011). Sarcopenia may have a negative influence on both chewing ability and oral function. A Japanese survey of elderly individuals (60 to 87 years old) reported that significant factors related to occlusal power were handgrip strength in males, walking speed for $5 \mathrm{~m}$ in both genders, and body muscle volume in females (Kono, 2009). These findings suggest the possibility that oral sarcopenia induces a negative spiral of systemic health conditions including decreased levels of appetite and activities of daily living, as well as deterioration of psychosomatic health conditions, such as occurrence of depression, though the causal relationship remains unclear.

\subsection{Brain activity}

Functional magnetic resonance imaging (fMRI) is a new tool for testing specific hypotheses regarding the anatomical regions involved in processing sensory and motor information in the human brain. Onozuka et al. (2002) assessed the effects of aging on brain regional activity associated with chewing in subjects with intact dentition. Chewing resulted in a bilateral increase in blood oxygenation level-dependent (BOLD) signals in the sensorimotor cortex, cerebellum, thalamus, supplementary motor area, and insula, and a unilateral increase in the right prefrontal area. Interestingly, the increase in the right prefrontal area was remarkable in aged subjects and up to 4 times higher than that seen in young subjects (Onozuka et al., 2003). Grady et al. (2001) showed that increased right prefrontal cortex activity is associated with better memory performance. In elderly individuals, it is possible that chewing stimulates neuronal activity within a network between the right prefrontal cortex and hippocampus, which might be useful for maintaining cognitive function. Tooth loss/decreased chewing ability may lead to decreased cognitive ability or occurrence of dementia, which may or may not be a direct cause of cancer morbidity, though those would make the pathological conditions worse.

\subsection{Quality of life}

As described above, tooth loss results in decreased chewing ability and may influence the latitude of food selection. Consequently, comfort at the table as a major part of QOL may be decreased (Grath et al., 2000). Eating behavior may be related to the will to live and is expected to have a positive psychological effect (Teraoka et al., 1992). Since 1986, there have been several indexes presented for QOL assessment, such as Geriatric Oral Health Index (GOHAI) (Atchison \& Dolan, 1990) and Oral Health Impact Profile (OHIP) (Slade, 1997). In a comparison among 3 groups based on number of functional teeth, the GOHAI score in subjects with 24 to 32 teeth was higher than that in those with 0 to 19 and 20 to 23 teeth (Ikebe et al., 2007). In particular, factors related to chewing, eating, and speech influence QOL scores. In a Japanese intervention study of institutionalized elderly subjects, GOHAI scores were improved when denture treatment was performed (Naito et al. 2010). Another recent study reported a significant association between decreased chewing ability and decreased OHIP score (Inukai et al., 2010).

\subsection{Socioeconomic status}

The number of teeth is an indicator of lifetime oral health, and therefore highly associated with socioeconomic status and access to dental care. Tooth loss can partly be explained as a 
consequence that reflects unhealthful behavior, which may be associated with socioeconomic status. A recent prospective cohort study of 1462 Swedish women investigated the relationship between tooth loss and cancer mortality/morbidity (Cabrera et al., 2005). Tooth loss independent of socioeconomic status variables was associated with increased all-cause mortality and cardiovascular disease mortality (HR, 1.36, 95\% CI, 1.181.58 , and $\mathrm{HR}, 1.46,95 \% \mathrm{CI}, 1.15-1.85$ per 10 missing teeth, respectively), while no associations were found between tooth loss and cancer mortality (HR, 1.16, 95\%CI, 0.90-1.49). Thus, the authors proposed that socioeconomic status was a stronger predictor of cancer as compared to tooth loss, while tooth loss may be more related to cardiovascular events, though the precise mechanism remains unknown. On the other hand, due to several limitations including the timing of tooth loss and residual confounding factors, a comment regarding their article noted that additional longitudinal studies with randomized controlled trials will be required before conclusions can be drawn (Joshipura \& Richie, 2005).

\section{Conclusion}

Herein, we reviewed the associations between cancer and tooth loss as a more objective assessment of dental status as compared to periodontal disease. Significant associations have been shown between tooth loss and site-specific cancer, including gastric, lung, and pancreatic cancers. However, evidence regarding tooth loss and cancer mortality/morbidity reported to date is somewhat equivocal, and does not suggest that the general population should be warned of an increased risk of developing cancer. Some of the associations require further investigations and evidence of possible mechanisms is needed. However, all members of the dental profession are encouraged to promote good oral health and this advice should be extended to targeted populations. Routine dental care as well as public dental health interventions may lead to promotion of overall health and longevity.

\section{References}

Abnet, C.C., Qiao, Y.L., Dawsey, S.M., Dong, Z-W., Tayler, P.R. \& Mark, S.D. (2005) Tooth loss is associated with increased risk of total death and death from upper gastrointestinal cancer, heart disease, and stroke in a Chinese population-based cohort. International of Journal of Epidemiology, Vol. 34, pp. 467-474.

Abnet, C.C., Qiao, Y.L., Mark, S.D., Dong, Z.W., Taylor, P.R. \& Dawsey, S.M. (2001) Prospective study of tooth loss and incident oesophageal and gastric cancers in China. Cancer Causes Control, Vol. 12, pp. 847-854.

Ansai, T. (2010) Association between chewing ability and cardiovascular disease in the 80year-old Japanese population, Proceedings of International Symposium for Global Oral Health Science Niigata 2010, pp. 22-23, Niigata, Japan, Oct 9, 2010.

Atchison, K.A. \& Dolan, T.A. (1990) Development of the geriatric oral health assessment index. Journal of Dental Education, Vol. 54, pp. 680-687.

Bundgaard, T., Wildt, J., Frydenberg, M., Elbrond, O. \& Nielsen, J.E. (1995) Case-control study of squamous cell cancer of the oral cavity in Denmark. Cancer Causes Control, Vol. 6, pp. 57-67.

Cabrera, C., Hakeberg, M., Ahlqwist, M., Wedel, H., Bjorkelund, C., Bengtsson, C. \& Lissner, L. (2005) Can the relation between tooth loss and chronic disease be explained by 
socio-economic status? A 24-year follow-up from the population study of women in Gothenburg, Sweden. European Journal of Epidemiology, Vol. 20, pp. 229-236.

Cheng, K.K. \& Day, N. E. (1996) Nutrition and esophageal cancer. Cancer Causes Control, Vol. 7, pp. 33-40.

Correa, P.J. (2003) Bacterial infections as a cause of cancer. Journal of National Cancer Institute, Vol. 95, pp. E-3.

Demirer, T., Icli, F., Uznalimoglu, O. \& Kucuk, O. (1990) Diet and stomach cancer incidence. A case control study in Turkey. Cancer, Vol. 65, pp. 2344-2348.

Douglass, C.W., Berlin, J. \& Tennstedt, S. (1991) The validity of self-reported oral health status in the elderly. Journal of Public Health Dentistry, Vol. 51, pp. 220-222.

Eichner, K. (1955) Über eine gruppeneinteilung des lückengebisses für die prothetik. Deutsch Zahnärztlich Zeitschrift, Vol. 10, pp. 1831-1834 (in German).

Garrote, L.F., Herrero, R., Reyes, R.M., et al. (2001) Risk factors for cancer of the oral cavity and oro-pharynx in Cuba. British Journal of Cancer, Vol. 85, pp. 46-54.

Grady, C.L., Furey, M.L., Pietrini, P., Horwitz, B. \& Rapoport, S.I. (2001) Altered brain functional connectivity and impaired short-term memory in Altheimer's disease. Brain, Vol. 124: 739-756.

Grath, C. M., Bedi, R., \& Gilthorpe, M. S. (2000) Oral health related quality of life-view of the public in the United Kingdom. Community Dental Health, Vol. 17, pp. 3-7.

Guha, N., Boffetta, P., Wünsch, F.V., Eluf, N.J., Shangina, O., Zaridze, D., Curado, M.P., Koifman, S., Matos, E., Menezes, A., Szeszenia-Dabrowska, N., Fernandez, L., Mates, D., daudt, A.W., Lissowska, J., Dikshit, R. \& Brennan, P. (2007) Oral health and risk of squamous cell carcinoma of the head and neck and oesophagus: results of the two multicentric case-control. American Journal of Epidemiology, Vol. 166, pp. 1159-1173.

Hiraki, A., Matsuo, K., Suzuki, T., Kawase, T. \& Tajima, K. (2008) Teeth loss and risk of cancer at 14 common sites in Japanese. Cancer Epidemiology Biomarkers Prevention, Vol. 17, No. 5, pp. 1222-1227.

Homann, N., Tillonen, J., Rintamäki, H., Salaspuro, M., Lindqvist, C. \& Meurman, J.H. (2001) Poor dental status increases acetaldehyde production from ethanol in saliva: a possible link to increased oral cancer risk among heavy drinkers. Oral Oncology, Vol. 37, pp. 153-158.

Hujoel, P.P., Drangsholt, M., Spiekerman, C. \& DeRouen, T.A. (2000) Periodontal disease and coronary heart disease risk. Journal of the American Medical Association Vo. 284: 1406-1410.

Hujoel, P.P., Drangsholt, M., Spiekerman, C. \& Weiss, N.S. (2003) An exploration of the periodontitis-cancer association. Annals of Epidemiology, Vol. 13, pp. 312-316.

Hung, H.C., Willett, W., Ascherio, A., Rosner, B. A., Rimm, E. \& Joshipura, K. J. (2003) Tooth loss and dietary intake. Journal of the American Dental Association, Vol. 134, pp. 11851192.

Ikebe, K., Hazeyama, T., Morii, K., Matsuda, K., Maeda, Y. \& Nobuki, T. (2007) Impact of masticatory performance on oral health-related quality of life for elderly Japanese. International Journal of Prosthodontics, Vol. 20, pp. 478-485.

Ikebe, K., Sajima, H., Namba, H., Ono, T., Yamamoto, M., Yasui, S., Kita, S., Kibi, M., Iwase, K., Shimizu, Y., Okiyama, S., Hata, K., Yuri, K., Uehara, M., Yamaba, O. \& Nokubi, T. (1999) Oral and general health in the independent elderly. Part 2: Relation 
between mastication and general disease. Ronen Shigaku, Vol. 14, pp. 131-138 (in Japanese).

Inukai, M., Joh, M. T., Igarashi, Y. \& Baba, K. (2010) Association between perceived chewing ability and oral health-related quality of life in partially dentate patients. Health Quality of Life Outcomes, Vol. 8, pp. 118.

Joshipura, K.J., Ascherio, A. \& Manson, J.E. (1999) Fruit and vegetable intake in relation to risk of ischemic stroke. Journal of the American Medical Association, Vol. 282, pp. 12231229.

Joshipura, K.L. \& Richie, C. (2005) Commentary: Can the relation between tooth loss and chronic disease be explained by socio-economic status? European Journal of Epidemiology Vol. 20: 203-204.

Kanmori, H., Yoshihara, A., Ando, Y. \& Miyazaki, H. (2003) The effect of chewing ability on the dietary intake of healthy elderly people. Journal of Dental Health, Vol. 53, pp. 1322 (in Japanese).

Kono, R. (2009) Relationship between occlusal force and preventive factors for disability among community-dwelling elderly persons. Nippon Ronen Igakkai Zasshi, Vol. 46, pp. 55-62 (in Japanese).

Lee, M. S., Huang, Y. C., and Wahlqvist, M. L. (2010) Chewing ability in conjunction with food intake and energy status in later life affects survival in Taiwanese with the metabolic syndrome. Journal of the American Geriatrics Society, Vol. 58, pp. 1072-1080.

Marshall, J.R., Graham, S., Haughey, B.P., Shedd, D., O'Shea, R., Brasure, J., Wilkinson, G.S. \& West, D. (1992) Smoking, alcohol, dentition and diet in the epidemiology of oral cancer. European Journal Cancer B Oral Oncology, Vol. 28B, pp. 9-15.

Meyer, M.S., Joshipura, K., Giovannucci, E. \& Michaud, D.S. (2008) A review of the relationship between tooth loss, periodontal disease and cancer. Cancer Causes Control, Vol. 19, pp. 895-907.

Michaud D.S., Liu, Y., Meyer, M., Giovannucci, E. \& Joshipura, K. (2008) Peridontal disease, tooth loss, and cancer risk in male health professionals: a prospective cohort study. Lancet Oncology, Vol.9, pp. 550-558.

Michaud, D.S., Joshipura, K., Giovannucci, E. \& Fuchs, C.S. (2007) A prospective study of periodontal disease and pancreatic cancer in US male health professionals. Journal of National Cancer Institute, Vol. 99, pp. 171-175.

Naito, M., Kato, T., Fujii, W., Ozeki, M., Yokoyama, M., Hamajima, N. \& Saitoh, E. (2010) Effects of dental treatment on the quality of life and activities of daily living in institutionalized elderly in Japan. Archives of Gerontology and Geriatrics, Vol. 50, pp. 65-68.

Nowjack-Raymer, R. E. \& Sheiham, A. (2003) Association of edentulism and diet and nutrition in US adults. Journal of Dental Research, Vol. 82, pp. 123-126.

Okada, K., Sumiya, A., Enoki, Y., Izawa, S., Hasegawa, J. \& Tsutaya, M. (2011) Association between walking speed and oral function in the elderly. Nippon Ronen Igakkai Zasshi, Vol. 48, pp.114 (Supplement) (in Japanese).

Okuyama, N., Yamaga, T., Yoshihara, A., Nohno, K., Yoshitake, Y., Kimura, Y., Shimada, M., Nakagawa, N., Nishimura, M., Ohashi, M. \& Miyazaki, H. (2011) Influence of dental occlusion on physical fitness decline in a healthy Japanese elderly population. Archives of Gerontology and Geriatrics, Vol. 52, pp. 172-176. 
Onozuka, M., Fujita, M., Watanabe, K., Hirano, Y., Niwa, M., Nishiyama, K. \& Saito, S. (2002) Mapping brain region activity during chewing: a functional magnetic resonance imaging study. Journal of Dental Research, Vol. 81, pp. 743-746.

Onozuka, M., Fujita, M., Watanabe, K., Hirano, Y., Niwa, M., Nishiyama, K. \& Saito, S. (2003) Age-related changes in brain regional activity during chewing: a functional magnetic resonance imaging study. Journal of Dental Research, Vol. 82, pp. 657-660.

Papapanou, P.N. (1996) Periodontal disease: epidemiology. Annals of Periodontology Vol. 1, pp. 1-36.

Rosenquist, K. (2005) Risk factors in oral and oropharyngeal squamous cell carcinoma: a population-based case-control study in southern Sweden. Swedish Dental Journal (Supplement), Vol. 179, pp. 1-66.

Shapiro, K.B. (1991) Quantitative relationship between oral nitrate-reducing activiry and the endogenous formation of $\mathrm{N}$-nitrosoamino acids in humans. Food Chemistry Toxicology, Vol. 29, pp. 751-755.

Sheiham, A., Steele, J. G., Marcenes, W., Lowe, C., Finch, S., Bates, C. J., Prentice, A. \& Walls, A. W. G. (2001) The relationship among dental status, nutrient intake, and nutritional status in older people. Journal of Dental Research, Vol. 80, No. 2, pp. 408413.

Slade, G.D. (1997) Derivation and validation of a short-form oral health impact profile. Community Dentistry and Oral Epidemiology, Vol. 25, pp. 284-290.

Stolzenberg-Solomon, R., Dodd, K.W., Blaser, M.J., Virtamo, J., Taylor, P.R. \& Albanes, D. (2003) Tooth loss, pancreatic cancer, and Helicobacter pylori. The American Journal of Clinical Nutrition, Vol. 78, pp. 176-181.

Takata, Y., Ansai, T., Awano, S., Hamasaki, T., Yoshitake, Y., Kimura, Y., Sonoki, K., Wakisaka, M., Fukuhara, M. \& Takehara, T. (2004) Relationship of physical fitness to chewing in an 80-year-old population. Oral Diseases, Vol. 10, pp. 44-49.

Teraoka, K., Nagai, H., Shibata, H., Okada, S \& Takeuchi, T. (1992) Effect of eating ability on physical activities in the elderly. Journal of Dental Health, Vol. 42, pp. 2-6 (in Japanese).

Tsai, A. C. and Chang, T. L. (2011) Association of dental prosthetic condition with food consumption and the risk of malnutrition and follow-up 4-year mortality in elderly Taiwanese. Journal of Nutrition Health and Aging, Vol. 15, 265-270.

Tu, Y-K., Galobardes, B., Smith, G. D., McCarron, P., Jeffreys, M. \& Gilthorpe, M. S. (2007) Associations between tooth loss and mortality patterns in the Glasgow alumni cohort. Heart, Vol. 93, pp. 1098-1103.

Wolff, G. \& Lauter, J. (1976) On the epidemiology of gastric cancer. Archiv für Geschwulstforschung, Vol. 46, pp. 1-14.

Wu, T., Trevisan, M., Genco, R.J. et al. (2000) Periodonatal disease and risk of cerebrovascular disease: the first national health and nutrition examination survey and its follow-up study. Archives of Internal Medicine Vol. 160: 2749-2755.

Yamaga, T., Yoshihara, A., Ando, Y., Yoshitake, Y., Kimura, Y., Shimada, M., Nishimuta, M. \& Miyazaki, H. (2002) Relationship between dental occlusion and physical fitness in an elderly population. J. Gerontol. A Biol. Sci. Med. Sci, Vol. 57, pp. M616-620.

Yoshida, M., Morikawa, H., Kanehisa, Y., Taji, T., Tsuga, K. \& Akagawa, Y. (2005) Functional dental occlusion may prevent falls in elderly individuals with dementia. Journal of American Geriatrics Society, Vol. 53, pp. 1631-1632. 
Yoshihara, A., Watanabe, R., Nishimuta, M., Hanada, N. \& Miyazaki, H. (2005) The relationship between dietary intake and number of teeth in elderly Japanese subjects. Gerodontology, Vol. 22, pp. 211-218.

Zheng, T.Z., Boyle, P., Hu, H.F., Duan, J., Jian, P.J., Ma, D.Q., Shui, L.P., Nui, S.R., Scully, C. \& MacMahon, B. (1990) Dentition, oral hygiene and risk of oral cancer: a case control study in Beijing, People's Republic of China. Cancer Causes Control, Vol. 1, pp. 235-241. 


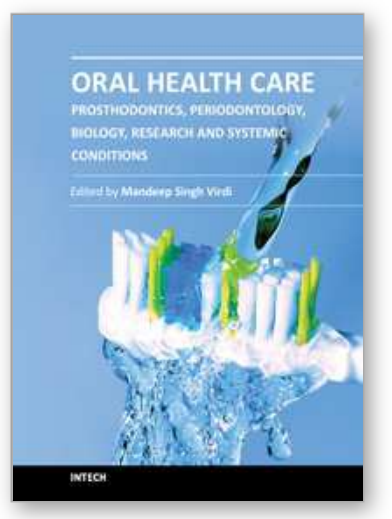

\author{
Oral Health Care - Prosthodontics, Periodontology, Biology, \\ Research and Systemic Conditions \\ Edited by Prof. Mandeep Virdi
}

ISBN 978-953-51-0040-9

Hard cover, 372 pages

Publisher InTech

Published online 29, February, 2012

Published in print edition February, 2012

Geriatric dentistry, or gerodontics, is the branch of dental care dealing with older adults involving the diagnosis, prevention, and treatment of problems associated with normal aging and age-related diseases as part of an interdisciplinary team with other healthcare professionals. Prosthodontics is the dental specialty pertaining to the diagnosis, treatment planning, rehabilitation, and maintenance of the oral function, comfort, appearance, and health of patients with clinical conditions associated with missing or deficient teeth and/or oral and maxillofacial tissues using biocompatible materials. Periodontology, or Periodontics, is the specialty of oral healthcare that concerns supporting structures of teeth, diseases, and conditions that affect them. The supporting tissues are known as the periodontium, which includes the gingiva (gums), alveolar bone, cementum, and the periodontal ligament. Oral biology deals with the microbiota and their interaction within the oral region. Research in oral health and systemic conditions concerns the effect of various systemic conditions on the oral cavity and conversely helps to diagnose various systemic conditions.

\title{
How to reference
}

In order to correctly reference this scholarly work, feel free to copy and paste the following:

Toshihiro Ansai and Yutaka Takata (2012). Association Between Tooth Loss and Cancer Mortality in Elderly Individuals, Oral Health Care - Prosthodontics, Periodontology, Biology, Research and Systemic Conditions, Prof. Mandeep Virdi (Ed.), ISBN: 978-953-51-0040-9, InTech, Available from:

http://www.intechopen.com/books/oral-health-care-prosthodontics-periodontology-biology-research-andsystemic-conditions/association-between-tooth-loss-and-cancer-mortality-in-elderly-subjects

\section{INTECH}

open science | open minds

\section{InTech Europe}

University Campus STeP Ri

Slavka Krautzeka 83/A

51000 Rijeka, Croatia

Phone: +385 (51) 770447

Fax: +385 (51) 686166

www.intechopen.com

\section{InTech China}

Unit 405, Office Block, Hotel Equatorial Shanghai

No.65, Yan An Road (West), Shanghai, 200040, China 中国上海市延安西路65号上海国际贵都大饭店办公楼 405 单元

Phone: +86-21-62489820

Fax: +86-21-62489821 
(C) 2012 The Author(s). Licensee IntechOpen. This is an open access article distributed under the terms of the Creative Commons Attribution 3.0 License, which permits unrestricted use, distribution, and reproduction in any medium, provided the original work is properly cited. 